\title{
Video-assisted thoracoscopic surgery versus open lobectomy for stage I lung cancer: A meta-analysis of long-term outcomes
}

\author{
ZHENGJUN LI ${ }^{1}$, HONGXU LIU' ${ }^{1}$ and $\mathrm{LE} \mathrm{LI}^{2}$ \\ Departments of ${ }^{1}$ Thoracic Surgery, and ${ }^{2}$ General Surgery, First Affiliated Hospital, \\ China Medical University, Shenyang, Liaoning 110001, P.R. China
}

Received November 19, 2011; Accepted January 20, 2012

DOI: $10.3892 /$ etm.2012.485

\begin{abstract}
The present study aimed to evaluate the evidence comparing video-assisted thoracoscopic surgery (VATS) and open lobectomy for the treatment of stage I lung cancer using meta-analytical techniques. A literature search was undertaken until July 2011 to identify comparative studies evaluating survival rates, recurrence rates and complications. Pooled odds ratios (OR) and 95\% confidence intervals (95\% CI) were calculated with either the fixed- or random-effects model. These studies included a total of 1,362 patients: 668 treated with VATS and 694 treated with open lobectomy. The overall survival was significantly higher in patients treated with VATS than with open thoracotomy $(\mathrm{OR}=2.01,95 \%$ CI $1.44-2.78)$ at 5 years. However, there was no statistically significant difference in 1.3-year overall survival between the VATS and open lobectomy groups $(\mathrm{OR}=3.21,95 \%$ CI $0.77-13.40$; $\mathrm{OR}=0.91,95 \%$ CI $0.49-1.70)$. The data did not demonstrate a significant difference in locoregional recurrence $(\mathrm{OR}=0.58$, 95\% CI 0.33-1.03) compared to the open lobectomy group, but suggested a reduced systemic recurrence rate $(\mathrm{OR}=0.52$, 95\% CI 0.23-0.82) and complications (OR $=0.36,95 \% \mathrm{CI}$ 0.23-0.57) of VATS. VATS was superior to open lobectomy for the prognosis of stage I lung cancer. However, the findings have to be carefully interpreted due to the lower levels of evidence.
\end{abstract}

\section{Introduction}

Lung cancer is the most common malignant tumor in the world. With the improvement in diagnostic technology, more and more stage I lung cancer is identified. Video-assisted thoracoscopic surgery (VATS) was first reported by Levi et al in 1990 (1). The inital clinical reports on video-assisted thoracoscopic surgery lobectomy, published from 1993 onward, were either preliminary or involved a small number

Correspondence to: Dr Hongxu Liu, Department of Thoracic Surgery, First Affiliated Hospital, China Medical University, Shenyang, Liaoning 110001, P.R. China

E-mail: hongxuliu@yahoo.com

Key words: lung cancer, meta-analysis, video-assisted thoracoscopic surgery, open lobectomy, prognosis of patients, which indicated the feasibility and safety of VATS lobectomy (2-6). Since then, VATS has become an attractive surgical procedure for benign diseases, due to its low invasiveness $(7,8)$. As the experience with VATS for benign diseases increased, VATS was gradually adopted for the treatment of lung cancer. Thereafter, VATS lobectomy for elderly patients and series involving a larger number of patients were reported (9-14). VATS lobectomy is now accepted, if not universally, at least as an alternative surgical option for early-stage lung cancer.

The advantages of VATS lobectomy, which include less pain and better pulmonary function in the early postoperative period, have been previously reported. However, there are various controversies regarding the prognosis of VATS vs. open lobectomy for stage I lung cancer. Immune system function in the early postoperative period was found to be better preserved in patients who underwent VATS lobectomy. Curability after VATS lobectomy was also reported to be similar to the generally accepted curability rate after open lobectomy. Several investigators reported that the survival rate after VATS lobectomy was similar to that after open lobectomy. Sawada et al (15), Sugiura et al (16), Tashima et al (17) and Flores et al (18) reported that there was no statistically significant difference in survival between the VATS and open lobectomy in early-stage lung cancer. However, this meta-analysis showed that VATS had significantly better survival rates in terms of overall survival at 5 years.

\section{Materials and methods}

Study selection. Electronic searches were performed of the MEDLINE, Cochrane Controlled Trial Register (CENTRAL) and EMBASE databases until July 2011. The following Mesh search headings were used: (VATS, video-assisted thoracoscopic or video-assisted thoracoscopic surgery), (open or conventional or standard lobectomy), (lung cancer or lung carcinoma), (randomized controlled trials) and (comparative study) in English (Fig. 1).

Data extraction and quality assessment. Data were extracted by three independent observers using standardized forms. The recorded data included the number of patients, overall survival and local recurrence rates, systemic recurrence and complications. The quality of all selected articles was ranked 


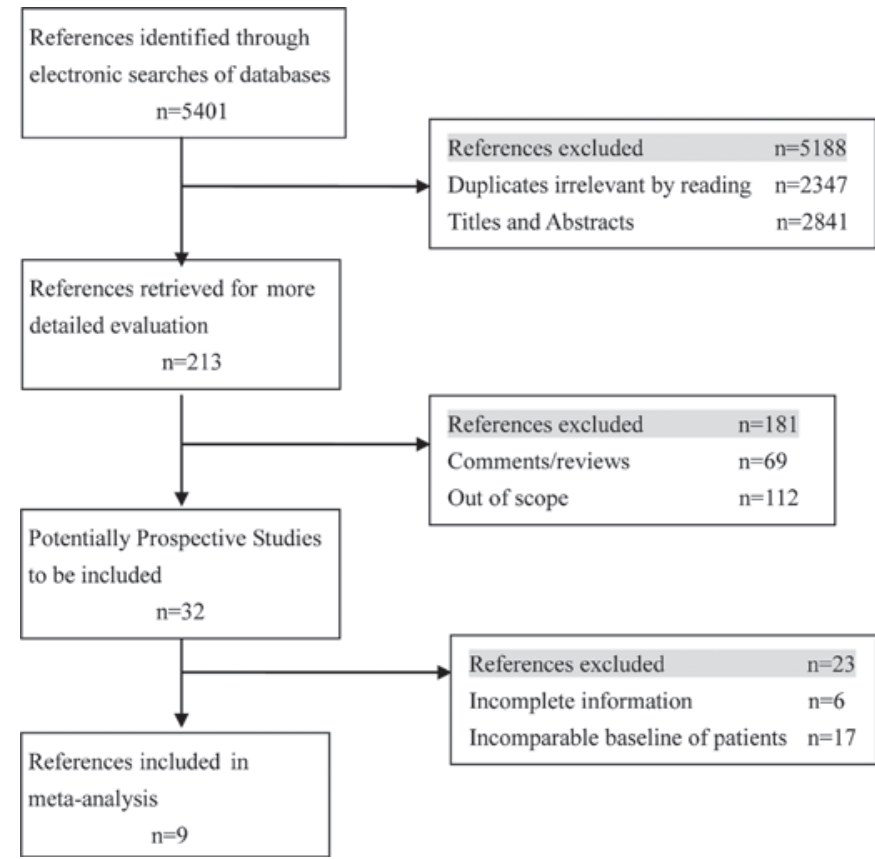

Figure 1. Identification of studies for inclusion.

in accordance with the score of the non-randomized controlled clinical trial quality evaluation standard.

Study selection criteria. Inclusion criteria for this study were as follows: i) no extrapulmonary metastasis; ii) no previous treatment of lung cancer; iii) patients with clinical stage or pathological stage I; iv) good lung function and all patients tolerated open lobectomy; v) no previous or simultaneous malignancies; vi) patients were suitable for treatment with either VATS or open lobectomy, and vii) the baseline characteristics of patients were similar.

Criteria for exclusion. Abstracts, letters, editorials and expert opinions, reviews without original data, case reports and studies lacking control groups were excluded. The following studies were also excluded: i) those dealing with unresectable lung cancer or recurrence after lobectomy, and ii) those with no clearly reported outcomes of interest.

\section{Surgical technique}

Open lobectomy. One-lung ventilation was used and the patient was placed in a lateral decubitus position. A posterolateral or lateral incision was performed in the 4 th or 5 th intercostal spaces. No or one rib adjacent to the thoracotomy was resected. A rib retractor was used to open the wound and spread the intercostal spaces. For right lung resection, mediastinal lymphadenectomy was performed completely; for left lung resection, the botallo ligament and hillal and carinal lymph nodes were dissected.

VATS lobectomy. In VATS lobectomy, two or three trocars were placed for a thoracoscope or instruments. Then, 4- to 8-cm access thoracotomy was placed along the anterior axillary line in the 4th intercostal space or posterior axillary line in the 5th intercostal space, and one or two or more access ports were added. Dissection of the pulmonary vessels and bronchi are performed in the same manner as in open lobectomy, and moderate adhesions or absent fissures are not contraindications to VATS resection. Mediastinal lymph node dissection is also performed in patients with non-small lung cancer, similar to open lobectomy techniques $(19,20)$. A rib spreader was not used. The resected lobe was placed in a plastic bag within the chest and then extracted intact via the anterior utility port.

Statistical analysis. The meta-analysis was performed using the software package RevMan 5.1.0. Odds ratio (OR) or mean difference with $95 \%$ confidence intervals $(95 \% \mathrm{CI})$ were calculated for dichotomous outcomes and continuous outcomes, respectively. A random-effects model and a fixed-effect model were used using 'intention-to-treat' analysis. If results were not different between the two models, the random-effects model was reported, as this model was used for the indirect comparisons. If results differed between the two models, both results were reported. Heterogeneity was explored by $\chi^{2}$ test and $\mathrm{I}^{2}$. $\mathrm{I}^{2}<25 \%$ and $\mathrm{I}^{2}>50 \%$ reflect a small and large inconsistency, respectively. $\mathrm{P}<0.05$ was considered to indicate a statistically significant difference.

Publication bias. A funnel plot was used to explore bias. Asymmetry in the funnel plot of the trial size against treatment effect was used to assess the risk of bias.

\section{Results}

Description of studies. Of 1,362 patients in 9 studies, 668 were allocated to the VATS group, whereas 694 were allocated to the open lobectomy group to evaluate their therapeutic effects on stage I lung cancer. Patient characteristics and evaluation index are shown in Table I. Three clinical stage I studies (23-25) postoperatively reported that pathological N1 and N2 diseases were found in 14 and 17 patients, respectively, from the open lobectomy group, and in 13 and 14 patients, respectively, from the VATS group. However, no significant difference was found between the groups $(\mathrm{P}=0.799)$. Patients reported from other studies were pathological stage I.

\section{Overall survival rates}

One-year survival rates. The meta-analysis (two trials reported these data) showed that there was no statistically significant difference in 1-year overall survival between the VATS and open lobectomy groups $(\mathrm{OR}=3.21,95 \% \mathrm{CI}$ 0.77-13.40; $\mathrm{P}=0.11$, with no evidence of significant heterogeneity (Table II).

Three-year survival rates. The meta-analysis (two trials reported these data) showed that there was no statistically significant difference in 3-year overall survival between the VATS and open lobectomy groups (OR=0.91,95\% CI 0.49-1.70; $\mathrm{P}=0.77)$, with no evidence of significant heterogeneity.

Five-year survival rates. The meta-analysis (all trials reported these data) showed that the 5-year survival rate in the open lobectomy group was significantly lower than that in the VATS group $(\mathrm{OR}=2.01,95 \%$ CI 1.44-2.78; $\mathrm{P}<0.0001)$, with certain heterogeneity (Fig. 2).

Locoregional recurrence rates. The meta-analysis (six trials reported these data) showed that there was no significantly 


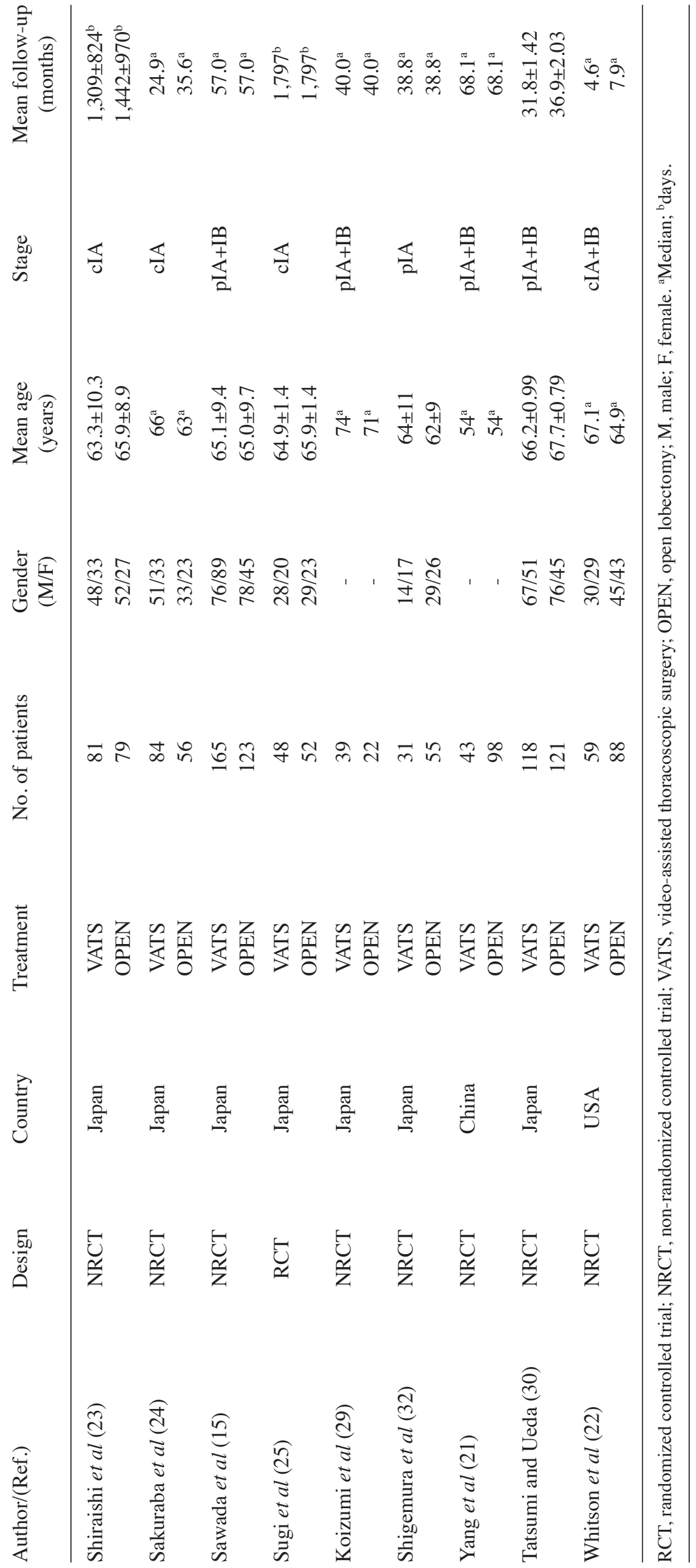


Table II. Summary of the results between VATS and OPEN in the management of stage I lung cancer.

\begin{tabular}{|c|c|c|c|c|c|c|}
\hline \multirow[t]{2}{*}{ Variables } & \multirow{2}{*}{$\begin{array}{l}\text { No. of studies } \\
\text { furnishing data } \\
\text { (Refs.) }\end{array}$} & \multicolumn{2}{|c|}{ Results } & \multirow[t]{2}{*}{ OR $(95 \% \mathrm{CI})$} & \multirow[t]{2}{*}{ P-value } & \multirow[t]{2}{*}{$\mathrm{I}^{2}(\%)$} \\
\hline & & VATS (\%) & OPEN (\%) & & & \\
\hline \multicolumn{7}{|l|}{ Overall survival } \\
\hline 1-year & $2(20,29)$ & 97.90 & 91.8 & $3.21(0.77-13.4)$ & 0.1100 & 0 \\
\hline 3-year & $2(22,25,29)$ & 83.50 & 83.3 & $0.91(0.49-1.70)$ & 0.7700 & 0 \\
\hline 5-year & $8(15,21,23-25,29,30,32)$ & 87.80 & 80.2 & $2.01(1.44-2.78)$ & $<0.0001$ & 17 \\
\hline Local recurrence & $6(23-25,29,30,32)$ & 4.98 & 8.3 & $0.58(0.33-1.03)$ & 0.0600 & 34 \\
\hline Systemic recurrence & $5(24,25,29,30,32)$ & 6.70 & 11.4 & $0.52(0.29-0.90)$ & 0.0200 & 0 \\
\hline Complications & $3(21,22,29,32)$ & 29.60 & 46.4 & $0.36(0.23-0.57)$ & $<0.0001$ & 59 \\
\hline
\end{tabular}

VATS, video-assisted thoracoscopic surgery; OPEN, open lobectomy; OR, odds ratio; CI, confidence interval.

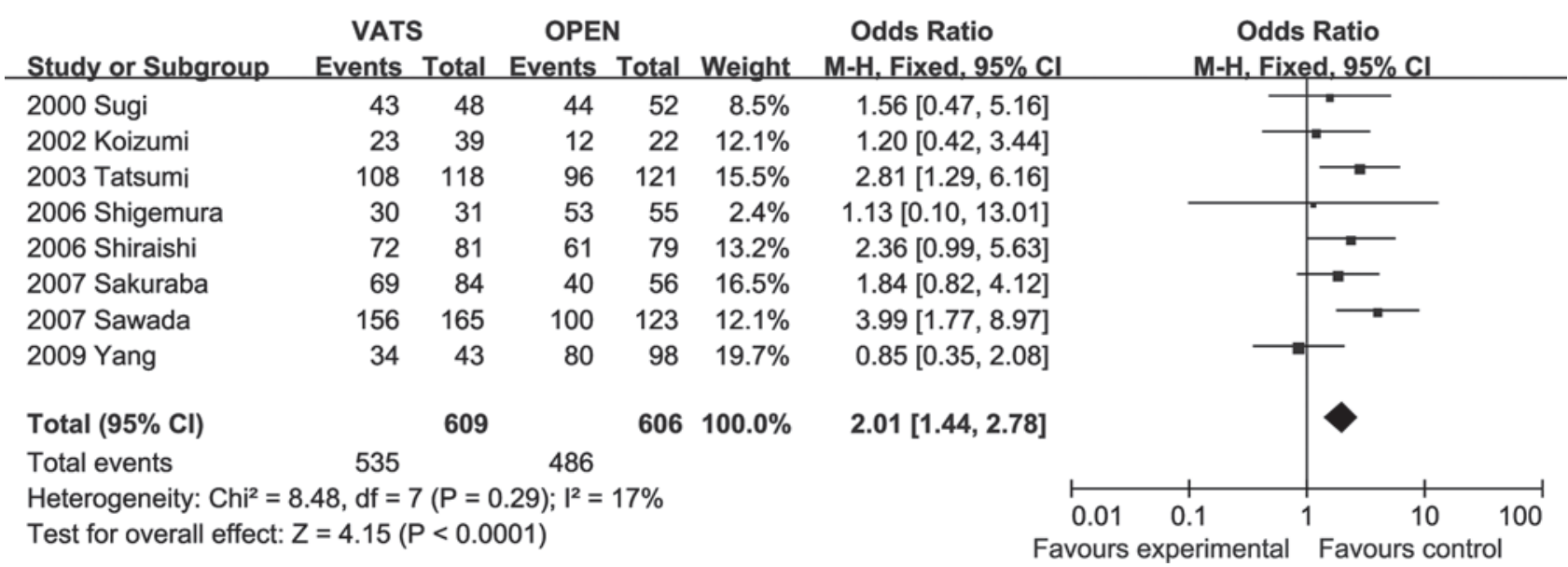

Figure 2. Five-year overall survival rates for VATS vs. open lobectomy for the treatment of stage I lung cancer.

statistical difference in the recurrence rate $(\mathrm{OR}=0.58,95 \% \mathrm{CI}$ $0.33-1.03 ; \mathrm{P}=0.07)$. However, in the VATS group $(4.98 \%)$ the incidence of complications was significantly less compared to the incidence in the open lobectomy group (8.31\%).

Systemic recurrence rates. The meta-analysis (four trials reported these data) showed that the recurrence rate in the lobectomy group was significantly higher than that in the VATS group $(\mathrm{OR}=0.52,95 \% \mathrm{CI} 0.23-0.82 ; \mathrm{P}=0.01)$, with no evidence of significant heterogeneity (Fig. 3).

Complications. The meta-analysis (three trials reported these data) showed that there was significant difference in the incidence of complications favorable to the VATS group $(\mathrm{OR}=0.36$, 95\% CI 0.23-0.57; P<0.0001), with certain heterogeneity.

Sensitivity analysis and publication bias. Publication bias may exist when no significant findings remain unpublished, thus artificially inflating the apparent magnitude of an effect.

Complication, survival and recurrence rates following VATS or open lobectomy for the treatment of stage I lung cancer were calculated by the fixed-effects model and randomeffects model, respectively. The results were similar and the combined results were highly reliable.
Funnel plots of the study results are shown in Fig. 4. The funnel plots concerning the 5-year overall survival rates following VATS or open lobectomy for the treatment of stage I lung cancer showed asymmetry, which suggested that there was some publication bias.

\section{Discussion}

Meta-analysis, a quantitative technique for therapeutic evaluation, may be used when controversy persists after several trials. We acknowledge that a very limited number of quality randomized controlled trials (RCTs) were available and included in this meta-analysis. The main reason for this is that it remains a challenge to conduct clinical research trials with randomization support and double blinding, both of which are effective means of preventing bias and improving the objectivity of clinical evidence for both the efficacy and the safety of any approved medical product or procedure or device. Although meta-analysis has traditionally been applied and is best confined to RCT, meta-analytical techniques using non-RCT may be a valid method in certain clinical settings in which either the number or the sample size of RCT is insufficient (26).

This meta-analysis suggested that the incidence of complications after VATS for the treatment of stage I lung cancer were 


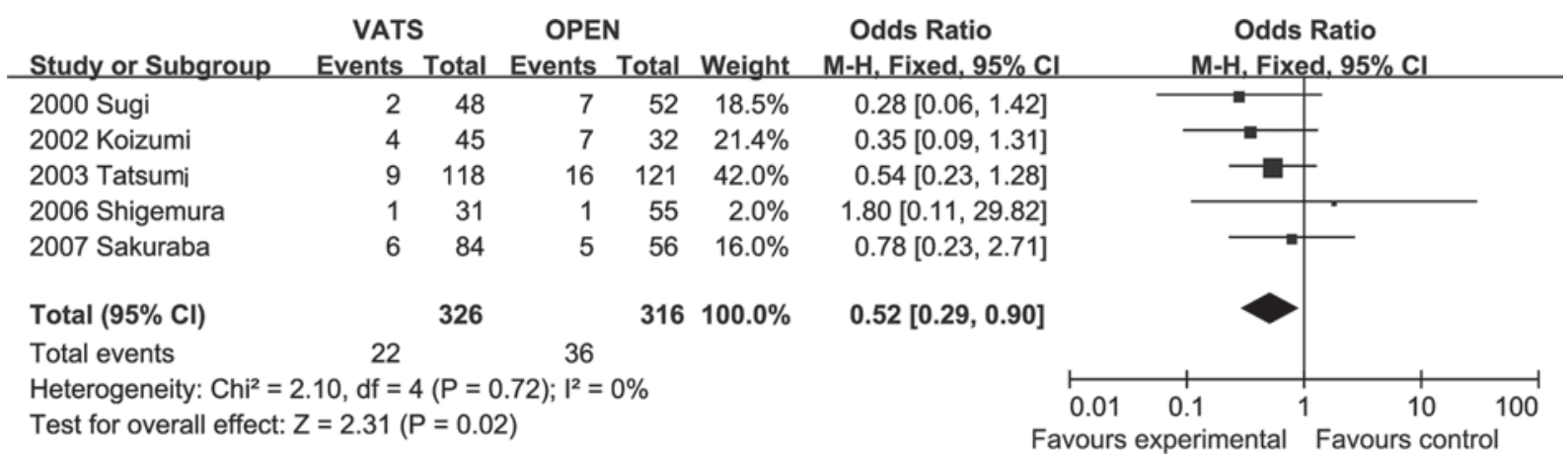

Figure 3. Systemic recurrence rates of VATS vs. open lobectomy for the treatment of stage I lung cancer.

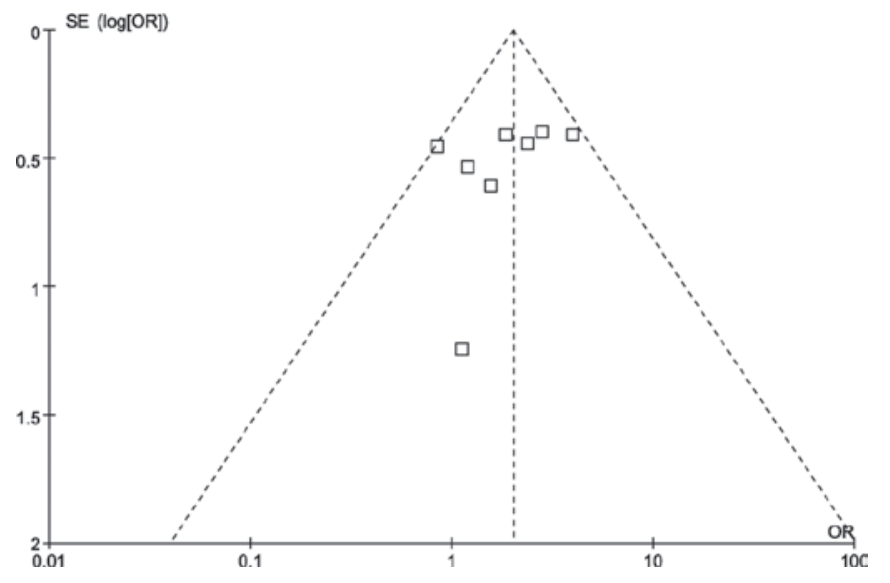

Figure 4. Funnel plot of the outcome of 5-year overall survival rates.

less than that in the open lobectomy group, which obviously embodied the microinvasive characterization of VATS. VATS is a minimally invasive technique that has been used in the clinic in the 1990s. Advocates of VATS lobectomy emphasize that this minimally invasive procedure is associated with less tissue trauma, reduced postoperative pain and a shorter hospital stay. McKenna et al (27) reported the largest single-institutional series on VATS lobectomy to date. In their study of 1,100 patients, the mortality rate was $0.8 \%$ and the morbidity rate was $15.3 \%$. Several studies reported that VATS resulted in superior rates of postoperative morbidity when compared to thoracotomy. VATS reduced intraoperative blood loss $(16,17,28-33)$, chest drain duration and length of hospital stay $(28,30,32,34,35)$. Also, this meta-analysis suggested that the incidence of complications after VATS was less than that in the open lobectomy group, which obviously embodied the micro-invasive characterization of VATS. These facts suggest that, in the hands of experienced surgeons, VATS lobectomy is a safe procedure. The advantages of VATS lobectomy have been previously reported, and the survival rates after VATS lobectomy are at the very least identical to those after open lobectomy.

Rare reports can be found on the long-term efficacy for VATS lobectomy, most of which are based on follow-up periods of 2 or 3 years and provide survival rates or predicted 5 -year survival rates calculated by the Kaplan-Meier method. This meta-analysis showed that VATS had significantly better survival rates in terms of overall survival at 5 years, but there was no statistically significant difference in 1.3 -year overall survival between the VATS and open lobectomy groups. This could be partly explained by the reduced invasiveness and improvements in surgical techniques. The minimal invasiveness of VATS lobectomy may reduce the immunosuppressive cytokine effect (36). Craig et al (37) demonstrated that VATS pulmonary lobectomy is associated with reduced peri-operative changes in acute phase responses. This finding may have implications for peri-operative tumor immuno-surveillance in lung cancer patients. Observations indicate that VATS is associated with better preserved cellular immunity and less immunosuppression when compared to open lobectomy during the immediate postoperative period, and less disturbance of inflammatory and immunomodulatory mediators following VATS may have additional impact upon tumor biological behavior (38). The short-term immunological advantages may improve long-term survival and reduce systemic recurrence. Additionally, a longer operative duration may be another factor affecting long-term clinical outcome.

The high rate of recurrence after surgery is the main cause of late death of patients with lung cancer. The risk factors include tumor size, insufficient safety margin and tumor location. This meta-analysis suggests that there is no statistically significant difference between the two groups. It proved again that VATS is a safe and acceptable surgical procedure when compared to open surgery. Also, VATS lobectomy with lymph node dissection was similar to that carried out in open surgery (25). Three clinical studies (23-25) postoperatively reported that pathological N1 was found in 14 patients from the open group, and in 13 patients from the VATS group. These results were consistent with various previous reports in which $10-25 \%$ of the T1 patients were found to have lymph node metastasis $(39,40)$. Lymph node metastasis is a significant prognostic factor, and the frequency of metastasis is high for clinical stage I. Therefore, we do not omit mediastinal lymph node dissection. However, this meta-analysis showed that systemic recurrence rate in the group undergoing open lobectomy was significantly higher than that in the VATS group. This also was partly explained by the reduced invasiveness and preserved cellular immunity and less immunosuppression. The higher 5-year overall survival rates and similar 3-year overall survival rates in the VATS lobectomy group compared to the open lobectomy group may be explained by the lower systemic recurrence rates.

A growing body of evidence has shown that patients with a tumor of $2 \mathrm{~cm}$ or less in diameter have a better survival than those with a tumor of $2.1-3 \mathrm{~cm}$ associated with improved curability of stage IA lung cancers, which we speculate is one 
of the reasons for the better survival found in this meta-analysis (41-43). In addition, the extended survival may be further exaggerated by the limited number of patients available $(44,45)$. We considered that patient bias may be a critical bias, and it should have influence on survival. However, no studies have mentioned this issue. The pathological type is also associated with prognosis. Sawada et al (15) showed that BAC has been detected more and more frequently, and is generally considered to be associated with better prognosis than other types of adenocarcinoma. BAC should be distinct from other adenocarcinomas. The prognosis of BAC and BAC + papillary adenocarcinoma in VATS was greater compared to the open lobectomy group. The BAC group showed a $100 \%$ 5-year survival.

Limitations of the study. The conclusions of this meta-analysis are limited by various factors. First, the number of studies that are included is small. Only one randomized study (23) met our inclusion criteria. This may have led to false positive or false negative conclusions (risk of random errors). Second, the majority of data in the present study comes from non-RCTs; therefore the overall level of clinical evidence is low. Even the randomization procedure was unclear or inadequate in the trials (46).

There is a concern for publication bias in the studies included. Those surgeons with less than optimal experiences or outcomes inferior to a thoracotomy would likely be less than enthusiastic about publishing their data, if they were accepted for publication at all. However, a firm conclusion about bias is difficult to reach as the asymmetry of the funnel plot is minimal. In addition, funnel plots show asymmetry for reasons other than publication bias. Therefore, our pooled OR may be an overestimate of the true effect. Due to data constraints, this meta-analysis could not analyze the quality of life score and was unable to carry out stratified analyses of other possible confounding factors. If the method is to be more effective, then larger samples and randomized controlled studies with longer follow-up are required.

Furthermore, stage I includes IA and IB. Non-small lung cancer can be classified into adenocarcinoma, squamous cell carcinoma, large-cell carcinoma and adenosquamous carcinoma. However, we failed to separate the analysis because of the limited data of these trials.

In conclusion, VATS was superior to open lobectomy in the 5-year overall survival rates of patients with stage I lung cancer eligible for surgical treatments. VATS lobectomy is a beneficial alternative to open lobectomy for selected cases of pulmonary lesions and should be vigorously promoted, although the procedure is more complex than conventional open lobectomy. The successful completion of VATS lobectomy depends on adequate patient selection, instrumentation and experience of the surgeon. However, the findings have to be carefully interpreted due to the lower levels of evidence (systematic error and random error). Further RCTs are warranted to clarify the exact value of VATS and open lobectomy for stage I lung cancer.

\section{Acknowledgements}

The work was supported by the National Natural Science Foundation of China (Grant No. 30700821) and Liao Ning BaiQianWan Talents Program (Grant No.2011921038).

\section{References}

1. Levi JF, Kleinmann P, Riquet M and Debesse B: Percutaneous parietal pleurectomy for recurrent spontaneous pneumothorax. Lancet 336: 1577-1578, 1990

2. Kirby TJ, Mack MJ, Landreneau RJ and Rice TW: Initial experience with video-assisted thoracoscopic lobectomy. Ann Thorac Surg 56: 1248-1253, 1993.

3. De Letter J and Proot L: Thoracoscopic assisted lobectomy. Surg Laparosc Endosc 5: 12-16, 1995.

4. Walker WS, Carnochan FM and Tin M: Thoracoscopy assisted pulmonary lobectomy. Thorax 48: 921-924, 1993.

5. Roviaro G, Varoli F, Rebuffat C, Vergani C, D'Hoore A, Scalambra SM, Maciocco M and Grignani F: Major pulmonary resections: pneumonectomies and lobectomies. Ann Thorac Surg 56: 779-783, 1993.

6. Kirby TJ and Rice TW: Thoracoscopic lobectomy. Ann Thorac Surg 56: 784-786, 1993.

7. Cole FH Jr, Cole FH, Khandekar A, Maxwell JM, Pate JW and Walker WA: Video-assisted thoracic surgery: primary therapy for spontaneous pneumothorax? Ann Thorac Surg 60: 931-935, 1995

8. Sawada S, Watanabe Y and Moriyama S: Video-assisted thoracoscopic surgery for primary spontaneous pneumothorax: evaluation of indications and long-term outcome compared with conservative treatment and open thoracotomy. Chest 127: 2226-2230, 2005.

9. Giudicelli R, Thomas P, Lonjon T, Ragni J, Bulgare JC, Ottomani R and Fuentes P: Major pulmonary resection by videoassisted mini-thoracotomy. Initial experience in 35 patients. Eur J Cardiothorac Surg 8: 254-258, 1994.

10. Solaini L, Bagioni P and Grandi U: Role of video endoscopy in pulmonary surgery: present experience. Eur J Cardiothorac Surg 9: 65-68, 1995.

11. McKenna RJ Jr: Thoracoscopic lobectomy with mediastinal sampling in 80-year-old patients. Chest 106: 1902-1904, 1994.

12. Roviaro G, Varoli F, Rebuffat C, Vergani C, Maciocco M, Scalambra SM, Sonnino D and Gozi G: Video thoracoscopic staging and treatment of lung cancer. Ann Thorac Surg 59: 971-974, 1995.

13. Kirby TJ, Mack MJ, Landreneau RJ and Rice TW: Lobectomy - video-assisted thoracic surgery versus muscle-sparing thoracotomy. A randomized trial. J Thorac Cardiovasc Surg 109: 997-1002, 1995.

14. Asamura H, Nakayama H, Kondo H, Tsuchiya R and Naruke T: Video-assisted lobectomy in the elderly. Chest 111: 1101-1105, 1997.

15. Sawada S, Komori E, Yamashita M, et al: Comparison in prognosis after VATS lobectomy and open lobectomy for stage I lung cancer: retrospective analysis focused on a histological subgroup. Surg Endosc 21: 1607-1611, 2007.

16. Sugiura H, Morikawa T, Kaji M, Sasamura Y, Kondo S and Katoh H: Long-term benefits for the quality of life after videoassisted thoracoscopic lobectomy in patients with lung cancer. Surg Laparosc Endosc Percutan Tech 9: 403-408, 1999.

17. Tashima T, Yamashita J, Nakano S, et al: Comparison of videoassisted minithoracotomy and standard open thoracotomy for the treatment of non-small-cell lung cancer. Minim Invasive Ther Allied Technol 14: 203-208, 2005.

18. Flores RM, Park BJ, Dycoco J, et al: Lobectomy by videoassisted thoracic (VATS) versus thoracotomy for lung cancer. J Thorac Cardiovasc Surg 138: 11-18, 2009.

19. McKenna RJ Jr and Houck WV: New approaches to the minimally invasive treatment of lung cancer. Curr Opin Pulm Med 11: 282-286, 2005.

20. Shiraishi T, Shirakusa T, Miyoshi T, et al: A completely thoracoscopic lobectomy/segmentectomy for primary lung cancer - technique, feasibility, and advantages. Thorac Cardiovasc Surg 54: 202-207, 2006.

21. Yang X, Wang S and Qu J: Video-assisted thoracic surgery (VATS) compares favorably with thoracotomy for the treatment of lung cancer: a five-year outcome comparison. World J Surg 33: 1857-1861, 2009.

22. Whitson BA, Andrade RS, Boettcher A, Bardales R, Kratzke RA, Dahlberg PS and Maddaus MA: Video-assisted thoracoscopic surgery is more favorable than thoracotomy for resection of clinical stage I non-small cell lung cancer. Ann Thorac Surg 83: 1965-1970, 2007.

23. Shiraishi T, Shirakusa T, Hiratsuka M, Yamamoto $S$ and Iwasaki A: Video-assisted thoracoscopic surgery lobectomy for c-T1N0M0 primary lung cancer: its impact on locoregional control. Ann Thorac Surg 82: 1021-1026, 2006. 
24. Sakuraba M, Miyamoto H, Oh S, et al: Video-assisted thoracoscopic lobectomy vs. conventional lobectomy via open thoracotomy in patients with clinical stage IA non-small-cell lung carcinoma. Interact Cardiovasc Thorac Surg 6: 614-617, 2007.

25. Sugi K, Kaneda Y and Esato K: Video-assisted thoracoscopic lobectomy achieves a satisfactory long-term prognosis in patients with clinical stage IA lung cancer. World J Surg 24: 27-31, 2000.

26. Mathurin P, Raynard B, Dharancy S, et al: Meta-analysis: evaluation of adjuvant therapy after curative liver resection for hepatocellular carcinoma. Aliment Pharmacol Ther 17: $1247-1261,2003$

27. McKenna RJ Jr, Houck W and Fuller CB: Video-assisted thoracic surgery lobectomy: experience with 1,100 cases. Ann Thorac Surg 81: 421-426, 2006.

28. Ohbuchi T, Morikawa T, Takeuchi E and Kato H: Lobectomy: video-assisted thoracic surgery versus posterolateral thoracotomy. Jpn J Thorac Cardiovasc Surg 46: 519-522, 1998.

29. Koizumi K, Haraguchi S, Hirata T, et al: Video-assisted lobectomy in elderly lung cancer patients. Jpn J Thorac Cardiovasc Surg 50: $15-22,2002$.

30. Tatsumi A and Ueda Y: Video-assisted thoracic surgery for lung cancer: is it a feasible operation for stage I lung cancer? Jpn J Thorac Cardiovasc Surg 51: 646-650, 2003.

31. Muraoka M, Oka T, Akamine S, et al: Video-assisted thoracic surgery lobectomy reduces the morbidity after surgery for stage I non-small-cell lung cancer. Jpn J Thorac Cardiovasc Surg 54: 49-55, 2006

32. Shigemura N, Akashi A, Funaki S, et al: Long-term outcomes after a variety of video-assisted thoracoscopic lobectomy approaches for clinical stage IA lung cancer: a multi-institutional study. J Thorac Cardiovasc Surg 132: 507-512, 2006.

33. Tajiri M, Maehara T, Nakayama H and Sakamoto K: Decreased invasiveness via two methods of thoracoscopic lobectomy for lung cancer compared with open thoracotomy. Respirology 12: 207-211, 2007.

34. Petersen RP, Pham D, Burfeind WR, et al: Thoracoscopic lobectomy facilitates the delivery of chemotherapy after resection for lung cancer. Ann Thorac Surg 83: 1245-1250, 2007.

35. Park BJ, Zhang H, Rusch VW and Amar D: Video-assisted thoracic surgery does not reduce the incidence of postoperative atrial fibrillation after pulmonary lobectomy. J Thorac Cardiovasc Surg 133: 775-779, 2007.
36. Yim AP, Wan S, Lee TW and Arifi AA: VATS lobectomy reduces cytokine responses compared with conventional surgery. Ann Thorac Surg 70: 243-247, 2000.

37. Craig SR, Leaver HA, Yap PL, Pugh GC and Walker WS: Acute phasere sponses following minimal access and conventional thoracic surgery. Eur J Cardiothorac Surg 20: 455-463, 2001.

38. Ng CS, Wan S, Hui CW, Lee TW, Underwood MJ and Yim AP: Video-assisted thoracic surgery for early stage lung cancer can short-term immunological advantages improve long-term survival? Ann Thorac Cardiovasc Surg 12: 308-312, 2006.

39. Naruke T, Goya T, Tsuchiya R and Suematsu K: The importance of surgery to non-small cell carcinoma of lung with mediastinal lymph node metastasis. Ann Thorac Surg 46: 603-610, 1988.

40. Hata E, Hayakawa K, Miyamoto H and Hayashida R: Rationale for extended lymphadenectomy for lung cancer. Theor Surg 5: 19-25, 1990.

41. Wisnivesky JP, Yankelevitz D and Henschke CI: The effect of tumor size on curability of stage I non-small cell lung cancers. Chest 126: 761-765, 2004.

42. Sakao Y, Nakazono T, Sakuragi T, Natsuaki M and Itoh T: Predictive factors for survival in surgically resected clinical IA peripheral adenocarcinoma of the lung. Ann Thorac Surg 77: 1157-1162, 2004

43. Okada M, Nishio W, Sakamoto T, Uchino K, Yuki T, Nakagawa A and Tsubota N: Effect of tumor size on prognosis in patients with non-small cell lung cancer: the role of segmentectomy as a type of lesser resection. J Thorac Cardiovasc Surg 129: 87-93, 2005.

44. Roviaro G, Varoli F, Vergani C, Nucca O, Maciocco M and Grignani F: Long-term survival after video thoracoscopic lobectomy for stage I lung cancer. Chest 126: 725-732, 2004.

45. Walker WS, Codispoti M, Soon SY, Stamenkovic S, Carnochan F and Pugh G: Long-term outcomes following VATS lobectomy for non-small cell bronchogenic carcinoma. Eur J Cardiothorac Surg 23: 397-402, 2003.

46. Wood L, Egger M, Gluud LL, et al: Empirical evidence of bias in treatment effect estimates in controlled trials with different interventions and outcomes: meta-epidemiological study. BMJ 336: 601-605, 2008 